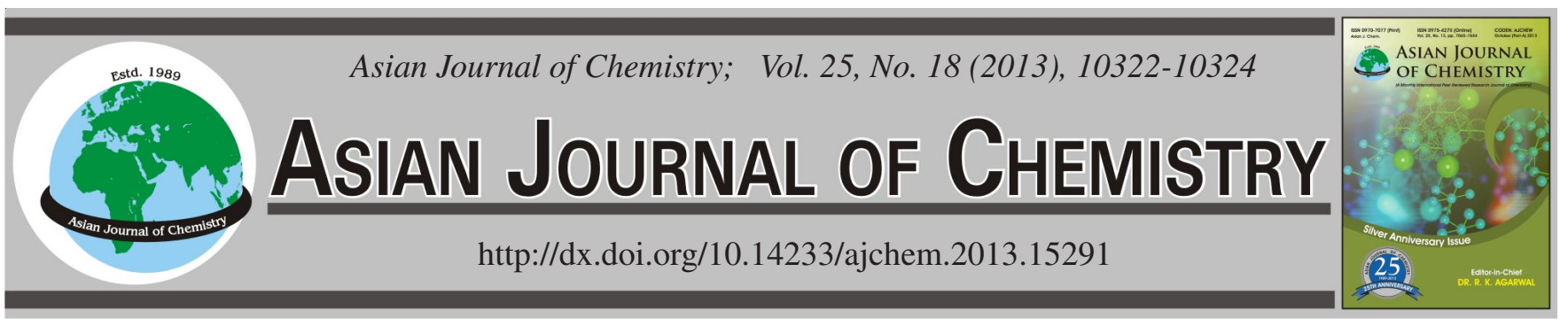

\title{
Boron Trifluoride Etherate Induced Stille Cross-Coupling Reaction of Aryltriazenes with Tributyl(phenyl)stannane Catalyzed by Recyclable Pd/C Catalyst
}

\author{
G.M. NAN ${ }^{1, *}$, J. ZHOU ${ }^{2}$ and W.L. YAN ${ }^{1}$
}

\begin{abstract}
${ }^{1}$ Xinjiang Laboratory of Phase Transitions and Microstructures of Condensed Matters, College of Chemistry and Biology, Yili Normal University, Yining, Xinjiang Province, P.R. China

${ }^{2}$ Comprehensive Technical Service Centre of Yili Entry-Exit Inspection and Quarantine Bureau, Yining, Xinjiang Province, P.R. China

*Corresponding author: Fax: +86 8124245; Tel: +86 8120048; E-mail: nanguangming02@ sohu.com
\end{abstract}

(Received: 6 February 2013;

Accepted: 14 November 2013)

AJC-14393

\begin{abstract}
A novel and efficient $\mathrm{Pd} / \mathrm{C}$-catalyzed Stille cross-coupling reaction of aryltriazenes with tributyl(phenyl)stannane has been realized in the presence of 1 equiv of $\mathrm{BF}_{3} \cdot \mathrm{OEt}_{2}$ under room temperature. The $\mathrm{Pd} / \mathrm{C}$ catalyst could be re-used several times and still retained its high activity. The present protocol, utilizes simple and recyclable catalyst, readily available starting materials and mild reaction conditions, provides an attractive methodology to a diverse range of biaryl products in moderate to excellent yields.
\end{abstract}

Key Words: Pd/C Catalyst, Stille cross-coupling, Aryltriazenes, Tributyl(phenyl)stannane, Boron trifluoride etherate, Recyclability.

\section{INTRODUCTION}

The efficient methods for the construction of carboncarbon bonds are an ongoing, central theme of research of organic synthesis ${ }^{1,2}$. In the past several decades, the transitionmetal-catalyzed Stille cross-coupling reaction has evolved as a powerful synthetic tool for the synthesis of unsymmetrical biaryls ${ }^{3}$, which are widely present in numerous classes of organic compounds, such as natural products, polymers, advanced materials, liquid crystals, ligands and molecules of medicinal interest ${ }^{4}$. Most of the reported Stille reactions are based on the use of aryl halides ${ }^{5-7}$, triflates ${ }^{8}$, sulfonyl chlorides ${ }^{9}$, sulfonates ${ }^{10}$ and carboxylates ${ }^{11}$ as one of the reaction components. As an alternative candidate for the electrophilic coupling partner, arenediazonium salts have also been employed in place of aryl halides in the Stille cross-coupling reaction ${ }^{12}$, and show high activity. However, arenediazonium salts are prone to decompose upon storage, which restricts their practical application. Aryltriazenes are stable and readily available compounds that can be easily prepared from the corresponding amines, which have been studied for their anticancer potential ${ }^{13,14}$, used as protecting groups in natural product synthesis ${ }^{15}$ and combinatorial chemistry ${ }^{16}$, incorporated into polymer ${ }^{17}$ and oligomer ${ }^{18}$ synthesis and used to form novel heterocycles ${ }^{19}$. Nevertheless, they have rarely been employed as coupling partners in transition-metal-catalyzed cross-coupling reactions to construct carbon-carbon bonds. Recently, we reported recyclable polymer-supported Pd-NHC complex catalyzed Suzuki-Miyaura cross-couplings of 1-aryltriazenes with arylboronic acids that gave biaryls in good to excellent yields under mild conditions $\mathrm{s}^{20}$. To the best of our knowledge, It have never been used for Stille cross-coupling reaction of aryltriazenes with organostannanes in recyclic catalytic system. Here, we report a novel and convenient boron trifluoride etherate induced recyclic catalytic system for Stille cross-coupling reaction of aryltriazenes with organostannanes in the presence of a simple $\mathrm{Pd} / \mathrm{C}$ catalyst, which shows excellent efficiency and can be easily recovered and reused several times and still retains high activity.

\section{EXPERIMENTAL}

General procedure for the preparation of aryltriazenes: A solution of aniline $(10 \mathrm{mmol}))$ in conc. $\mathrm{HCl}(2 \mathrm{~mL})$ was cooled in an ice bath while a solution of $\mathrm{NaNO}_{2}(10 \mathrm{mmol})$ in cold water $(1 \mathrm{~mL})$ was added dropwise. The resulting solution of the diazonium salt was stirred in the cold for $10 \mathrm{~min}$ and then added all at once to a chilled solution of $11 \mathrm{mmol}$ of pyrrolidine in $10 \mathrm{~mL}$ of $1 \mathrm{M} \mathrm{KOH}$ solution. The reaction mixture was stirred for $0.5 \mathrm{~h}$ in the cold and then the precipitate was isolated by filtration. The damp solid was then recrystallized from $10 \mathrm{~mL}$ of absolute EtOH or chromatographed on silica gel with 20:1 petroleum ether/ethyl acetate and dried.

General procedure for the Stille cross-couplings of aryltriazenes and tributyl(phenyl)stannane catalyzed by Pd/C catalyst: $\mathrm{Pd} / \mathrm{C}$ catalyst $(2 \mathrm{~mol} \% \mathrm{Pd})$, aryltriazenes $(0.5$ mmol), tributyl(phenyl)stannane $(0.75 \mathrm{mmol})$ were mixed in THF $(5 \mathrm{~mL})$. The mixture was stirred and added $\mathrm{BF}_{3} \cdot \mathrm{OEt}_{2}$ 
$(0.50 \mathrm{mmol})$ dropwise at room temperature under an argon atmosphere in $5 \mathrm{~min}$. When the reaction was completed, the catalyst was filtered and washed with ether $(3 \times 5 \mathrm{~mL})$ and then dried in vacuum for the next run. Solvent was evaporated under reduced pressure. The product was purified by silica gel column chromatography.

Compound constructs are charactered by ${ }^{1} \mathrm{H}$ and ${ }^{13} \mathrm{C}$ NMR. ${ }^{1} \mathrm{H}$ NMR spectra and ${ }^{13} \mathrm{C}$ NMR spectra were recorded on Varian INOVA $400 \mathrm{MHz}$ or Bruker Avance $600 \mathrm{MHz}$ spectrometer.

\section{RESULTS AND DISCUSSION}

Stille cross-coupling of aryltriazenes and organostannane catalyzed by the $\mathrm{Pd} / \mathrm{C}$ catalyst were investigated with the coupling of 1-(4-nitrophenyl)-2-(pyrrolidin-1-yl)diazene and tributyl(phenyl)stannane as a model reaction during optimization studies. Initially, the effect of $\mathrm{BF}_{3} \cdot \mathrm{OEt}_{2}$ was examined. We found that $\mathrm{BF}_{3} \cdot \mathrm{OEt}_{2}$ were essential for the formation of the biphenyl product. No production was generated in the absence of $\mathrm{BF}_{3} \cdot \mathrm{OEt}_{2}$ (Table-1, entry 1). Various solvents were then explored for this cross-coupling reaction (Table-1). Solvent significantly affected the yield. Among the solvents examined, THF was proven to be the best choice ( $82 \%$ yield, Table-1, entry 4). A good yield of the desired product (76\%) was obtained when the coupling was carried out in dioxane (Table1, entry 2). While, other solvents such as DME, $\mathrm{CH}_{3} \mathrm{CN}, \mathrm{DMF}$ and $\mathrm{CH}_{2} \mathrm{Cl}_{2}$ gave lower yields (Table-1, entries 3 and 5-7). The effect of the catalyst amount on the cross-coupling reaction was investigated. The amount of the $\mathrm{Pd} / \mathrm{C}$ catalyst employed in the reaction is of importance. No product was observed in the absence of the $\mathrm{Pd} / \mathrm{C}$ catalyst (Table-1, entry 8). When the amount of the $\mathrm{Pd} / \mathrm{C}$ catalyst was less than $2 \mathrm{~mol} \% \mathrm{Pd}$, the yield of the corresponding biaryl product was less than $90 \%$ (Table-1, entries 9-11). A high yield of $90 \%$ was obtained when 2 mol \% Pd was applied (Table-1, entry 12). Further increase of the catalyst loading did not obviously improve this reaction (Table-1, entry 13). During our research, we detected biphenyl as byproduct, which may be produced by the homecoupling reaction of tributyl(phenyl)stannane. Subsequently, the effect of the molar ratio of tributyl(phenyl)stannane to 1-(4-nitrophenyl)-2-(pyrrolidin-1-yl)diazene on the reaction was investigated (Table-1, entries 12 and 14-17). The yield of the corresponding biaryl product increased with increasing substrate the molar ratio. The highest yield $(97 \%)$ was obtained when the ratio was increased to 1.5 (Table-1, entry 15). Nevertheless, the yield did not further improve when the molar ratio was increased to 1.75 or 2.0 (Table-1, entries 16 and 17). After an extensive screening of the reaction parameters, the best yield of desired product (97\%) was obtained by employing $2 \mathrm{~mol} \% \mathrm{Pd} / \mathrm{C}$ catalyst and 1.0 equivalent of $\mathrm{BF}_{3} \cdot \mathrm{OEt}_{2}$ in THF at room temperature. Having defined the optimized reaction conditions, the recyclability of the $\mathrm{Pd} / \mathrm{C}$ catalyst for the Stille cross-coupling reactions of 1-(4-nitrophenyl)-2-(pyrrolidin1-yl)diazene and tributyl(phenyl)stannane was investigated (Table-2). The $\mathrm{Pd} / \mathrm{C}$ catalyst was reused four times and still remained high activity after being separated, washed and dried in vacuum under the same reaction conditions. Under our optimized reaction conditions, the scope and limitations of the reaction of various aryltriazenes with tributyl(phenyl)stannane

\begin{tabular}{|c|c|c|c|c|c|}
\hline \multicolumn{6}{|c|}{$\begin{array}{c}\text { TABLE-1 } \\
\text { Pd/C-CATALYZED CROSS-COUPLING OF } \\
\text { TRIBUTYL(PHENYL)STANNANE WITH 1-(4-NITROPHENYL)- } \\
\text { 2-(PYRROLIDIN-1-YL)DIAZENE: OPTIMIZATION } \\
\text { OF THE REACTION CONDITIONS }\end{array}$} \\
\hline Entry & $\begin{array}{c}\mathrm{Pd}(\mathrm{mol} \\
\%)\end{array}$ & Solvent & $\begin{array}{c}\text { Lewis } \\
\text { acids }\end{array}$ & $\begin{array}{l}\text { Molar } \\
\text { ratio }^{\text {b }}\end{array}$ & $\begin{array}{l}\text { Yield } \\
(\%)^{c}\end{array}$ \\
\hline 1 & 1.5 & Dioxane & - & 1.0 & - \\
\hline 2 & 1.5 & Dioxane & $\mathrm{BF}_{3} \cdot \mathrm{OEt}_{2}$ & 1.0 & 76 \\
\hline 3 & 1.5 & DME & $\mathrm{BF}_{3} \cdot \mathrm{OEt}_{2}$ & 1.0 & 68 \\
\hline 4 & 1.5 & THF & $\mathrm{BF}_{3} \cdot \mathrm{OEt}_{2}$ & 1.0 & 82 \\
\hline 5 & 1.5 & $\mathrm{CH}_{3} \mathrm{CN}$ & $\mathrm{BF}_{3} \cdot \mathrm{OEt}_{2}$ & 1.0 & 61 \\
\hline 6 & 1.5 & DMF & $\mathrm{BF}_{3} \cdot \mathrm{OEt}_{2}$ & 1.0 & 32 \\
\hline 7 & 1.5 & $\mathrm{CH}_{2} \mathrm{Cl}_{2}$ & $\mathrm{BF}_{3} \cdot \mathrm{OEt}_{2}$ & 1.0 & 50 \\
\hline 8 & - & THF & $\mathrm{BF}_{3} \cdot \mathrm{OEt}_{2}$ & 1.0 & - \\
\hline 9 & 0.5 & THF & $\mathrm{BF}_{3} \cdot \mathrm{OEt}_{2}$ & 1.0 & 51 \\
\hline 10 & 1.0 & THF & $\mathrm{BF}_{3} \cdot \mathrm{OEt}_{2}$ & 1.0 & 74 \\
\hline 11 & 1.5 & THF & $\mathrm{BF}_{3} \cdot \mathrm{OEt}_{2}$ & 1.0 & 82 \\
\hline 12 & 2.0 & THF & $\mathrm{BF}_{3} \cdot \mathrm{OEt}_{2}$ & 1.0 & 90 \\
\hline 13 & 2.5 & THF & $\mathrm{BF}_{3} \cdot \mathrm{OEt}_{2}$ & 1.0 & 90 \\
\hline 14 & 2.0 & THF & $\mathrm{BF}_{3} \cdot \mathrm{OEt}_{2}$ & 1.25 & 93 \\
\hline 15 & 2.0 & THF & $\mathrm{BF}_{3} \cdot \mathrm{OEt}_{2}$ & 1.5 & 97 \\
\hline 16 & 2.0 & THF & $\mathrm{BF}_{3} \cdot \mathrm{OEt}_{2}$ & 1.75 & 97 \\
\hline 17 & 2.0 & THF & $\mathrm{BF}_{3} \cdot \mathrm{OEt}_{2}$ & 2.0 & 96 \\
\hline
\end{tabular}

${ }^{a}$ Reaction conditions: 1-(4-nitrophenyl)-2-(pyrrolidin-1-yl)diazene (0.5 $\mathrm{mmol})$, Tributyl(phenyl)stannane (0.5-1 mmol), Pd/C (0.5-2.0 mol \% $\mathrm{Pd}), \mathrm{BF}_{3} \cdot \mathrm{OEt}_{2}(0.5 \mathrm{mmol})$, Solvent $(5 \mathrm{~mL})$, room temperature. ${ }^{\mathrm{b}} \mathrm{The}$ ratio of tributyl(phenyl)stannane to 1-(4-nitrophenyl)-2-(pyrrolidin-1yl)diazene. cIsolated by silica-gel column chromatography and based on 1-(4-nitrophenyl)-2-(pyrrolidin-1-yl)diazene.

\begin{tabular}{l} 
TABLE-2 \\
\hline Run \\
\hline Yield
\end{tabular}

were investigated. As shown in Table-3, a variety of biaryl products can be conveniently and efficiently obtained by this novel Stille cross-coupling reaction. The electronic nature of substituents and steric factors of aryltriazenes affected the yields of the cross-coupling products. Electron-withdrawing substituents on aryltriazenes gave better yields of biaryl products (Table-3, Entries 1-4), while donating groups on the aryltriazenes slightly reduced the yields (Table-3, entries 7-9). Steric hindrance of ortho substituents reduced the yields (Table-3, entries 6-8). Notably, good chemoselectivity was achieved with 1-(4-bromophenyl)-, 1-(4-iodophenyl)-2(pyrrolidin-1-yl)diazene (Table-3, entries 9-10), which suggested that triazenes were more active than the corresponding aryl bromides and iodides under these reaction conditions.

\section{Conclusion}

We have disclosed for the first time that the Stille crosscouplings of aryltriazenes and tributyl(phenyl)stannane can be catalyzed by a recyclable $\mathrm{Pd} / \mathrm{C}$ catalyst. The catalyst can be re-used several times and still retains high activity. The 


\begin{tabular}{|c|c|c|c|c|c|}
\hline $\mathrm{Ar}-\Lambda$ & $\begin{array}{r}\text { CROSS } \\
\text { AND } \\
\text { CA }\end{array}$ & $\begin{array}{l}\text { OUPI } \\
\text { IBUT } \\
\text { LYZF } \\
\end{array}$ & $\begin{array}{l}\text { ABLE- } \\
\text { IGS OF } \\
\text { (PHEN } \\
\mathrm{BY} \mathrm{Pd} / \\
\mathrm{SnBu}_{3}\end{array}$ & 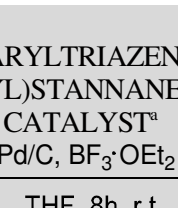 & \\
\hline Entry & $\mathrm{Ar}$ & $\mathrm{Ph}-$ & $\begin{array}{l}\text { Time } \\
\text { (h) }\end{array}$ & Product & $\begin{array}{l}\text { Yield } \\
(\%)^{b}\end{array}$ \\
\hline 1 & $4-\mathrm{NO}_{2} \mathrm{Ph}-$ & $\mathrm{Ph}-$ & 8 & & 97 \\
\hline 2 & $2-\mathrm{NO}_{2} \mathrm{Ph}-$ & $\mathrm{Ph}-$ & 10 & & 87 \\
\hline 3 & $3-\mathrm{NO}_{2} \mathrm{Ph}-$ & $\mathrm{Ph}-$ & 8 & & 96 \\
\hline 4 & 4-CNPh- & $\mathrm{Ph}-$ & 10 & & 87 \\
\hline 5 & Naphth- & $\mathrm{Ph}-$ & 12 & & 81 \\
\hline 6 & $\begin{array}{c}\text { 4- } \\
\mathrm{MeOPh}-\end{array}$ & $\mathrm{Ph}-$ & 11 & & 84 \\
\hline 7 & $\begin{array}{c}3- \\
\mathrm{MeOPh}-\end{array}$ & $\mathrm{Ph}-$ & 11 & & 86 \\
\hline 8 & $\begin{array}{c}2- \\
\mathrm{MeOPh}-\end{array}$ & $\mathrm{Ph}-$ & 12 & & 72 \\
\hline 9 & 4-IPh- & $\mathrm{Ph}-$ & 12 & & 70 \\
\hline 10 & 4-BrPh- & $\mathrm{Ph}-$ & 12 & & 75 \\
\hline \multicolumn{6}{|c|}{ 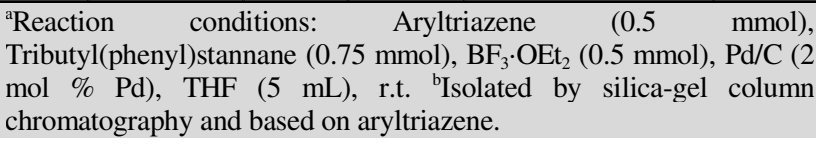 } \\
\hline
\end{tabular}

present protocol, which utilizes simple and recyclable catalyst, readily available starting materials and mild reaction conditions, provides an attractive approach to a diverse range of biaryl products in good to excellent yields.

\section{ACKNOWLEDGEMENTS}

This work was supported by the Fund of the Key Disciplines in the General Colleges and Universities of Xin Jiang Uygur Autonomous Region. Thanks are also due to the Analytical \& Testing Centre of Sichuan University for NMR measurements.

\section{REFERENCES}

1. J. Linshoeft, A.C.J. Heinrich, S.A.W. Segler, P.J. Gates and A. Staubitz, Org. Lett., 14, 5644 (2012).

2. I.P. Beletskaya and A.V. Cheprakov, Organometallics, 31, 7753 (2012).

3. C.C.C. JohanssonSeechurn, M.O. Kitching, T.J. Colacot and V. Snieckus, Angew. Chem., Int. Ed., 51, 5062 (2012).

4. J.K. Stille, Angew. Chem. Int. Ed., 25, 508 (1986).

5. S. Tang, S.H. Li and W.B. Yan, Tetrahedron Lett., 53, 6743 (2012).

6. J.R. Nabera and S.L. Buchwalda, Adv. Synth. Catal., 350, 957 (2008).

7. W.J. Zhou, K.H. Wang and J.X. Wang, Adv. Synth. Catal., 351, 1378 (2009).

8. K.C. Nicolaou, P.G. Bulger and D. Sarlah, Angew. Chem. Int. Ed., 44, 4442 (2005).

9. S.R. Dubbaka and P. Vogel, J. Am. Chem. Soc., 125, 15292 (2003)

10. A.H. Roy and J.F. Hartwig, J. Am. Chem. Soc., 125, 8704 (2003).

11. J.W. Labadie and J.K. Stille, J. Am. Chem. Soc., 105, 6129 (1983).

12. K. Kikukawa, K. Kono, F. Wada and T. Matsuda, J. Org. Chem., 48, 1333 (1983).

13. C.A. Rouzer, M. Sabourin, T.L. Skinner, E.J. Thompson and T.O. Wood, Chem. Res., 9, 172 (1996).

14. T.A. Connors, P.M. Goddard, K. Merai, W.C.J. Ross and D.E.V. Wilman, Biochem. Pharmacol., 25, 241 (1976).

15. K.C. Nicolaou, C.N.C. Boddy, H. Li, A.E. Koumbis, R. Hughes, S. Natarajan, N.F. Jain, J.M. Ramanjulu, S. Bräse and M.E. Solomon, Chem. Eur. J., 5, 2602 (1999).

16. S. Bräse, S. Dahmen and M. Pfefferkorn, J. Comb. Chem., 2, 710 (2000).

17. L. Jones II, J.S. Schumm and J.M. Tour, J. Org. Chem., 62, 1388 (1997).

18. J.S. Moore, Acc. Chem. Res., 30, 402 (1997).

19. W. Wirshun, M. Winkler, K. Lutz and J.C.J. Jochims, Chem. Soc. Perkin Trans. II, 1755 (1998).

20. G.M. Nan, F. Ren and M.M. Luo, Beilstein J. Org. Chem., 70, 1 (2010). 